\title{
Trends in the Treatment of Resectable Pancreatic Adenocarcinoma
}

\author{
Siavash Raigani, John Ammori, Kim Julian, and Jeffrey M. Hardacre \\ Department of Surgery, Division of Surgical Oncology, University Hospitals Seidman Cancer \\ Center, Case Western Reserve University, 11100 Euclid Avenue, Cleveland, OH 44106, USA \\ Jeffrey M. Hardacre: jeffrey.hardacre@uhhospitals.org
}

\begin{abstract}
Background-Multiple prospective, randomized trials have demonstrated that the addition of adjuvant therapy after surgical resection of pancreatic cancer improves survival compared to surgery alone. However, the optimal type of adjuvant therapy, chemotherapy alone, or chemotherapy combined with chemoradiation therapy remains controversial. Our aim was to examine the treatment trends for surgically resectable (stages I and II) pancreatic cancer in the USA using the National Cancer Database.
\end{abstract}

Methods-The National Cancer Database (NCDB) is a national oncology outcomes database for over 1,500 Commission on Cancer accredited cancer programs. Patients diagnosed with stage I-II pancreatic adenocarcinoma between 2003 and 2010 were selected from the NCDB Hospital Comparison Benchmark Reports. Attention was paid to the initial treatment regimen, such as surgery alone, surgery plus chemotherapy, or surgery plus chemoradiation. In addition, data on hospital setting (teaching hospitals vs. community hospitals) were collected and analyzed. The Cochran-Armitage test for trend was used to assess changes in treatment over time.

Results-Fifty-nine thousand ninety-four patients with stage I-II pancreatic adenocarcinoma were included in the analysis. Between 2003 and 2010, the use of surgery alone as first course treatment of stage II disease decreased significantly at both teaching hospitals and community hospitals among patients who underwent surgery $(P<0.0001$ for both cases). In the same period, the use of chemotherapy in addition to surgery as treatment of stage I and II disease increased at least twofold at both hospital settings ( $P<0.0001$ for all cases). Treatment with surgery plus chemoradiation decreased significantly for both stages in both hospital settings $(P<0.0001$ for all cases). Nonsurgical treatment for stage II disease was surprisingly high and significantly increased over time ( $P<0.001$ for both hospital types), ranging from approximately $30-37 \%$ at teaching hospitals and $39-47 \%$ at community hospitals.

Conclusion-Data from the NCDB from 2003 to 2010 illustrate changes in the adjuvant treatment of pancreatic cancer. The use of chemotherapy alone as adjuvant therapy increased whereas the use of multimodality therapy decreased. In addition, there remains an alarmingly high rate of nonsurgical therapy for stage I and II disease.

(C) 2013 The Society for Surgery of the Alimentary Tract

Correspondence to: Jeffrey M. Hardacre, jeffrey . hardacre@uhhospitals .org. 


\section{Keywords}

Pancreatic cancer; Surgery; Adjuvant therapy

\section{Introduction}

Exocrine pancreatic cancer remains one of the leading causes of cancer death in the USA.

Nearly 44,000 new cases are identified annually, and most of these patients are expected to die from their disease. ${ }^{1}$ Surgical resection is integral to a hope for cure in patients with pancreatic cancer. However, additional therapies are needed to improve survival.

Survival for patients with resected pancreatic cancer has improved in the past several decades with the addition of adjuvant therapy compared to surgery alone. ${ }^{2}$ Multiple randomized, controlled trials have shown that the addition of adjuvant chemotherapy or chemoradiation improves survival compared to observation following surgery. ${ }^{3-5}$ However, no consensus exists regarding the optimal approach to adjuvant therapy, namely, chemotherapy alone or chemotherapy combined with chemoradiation. 6,7

The National Comprehensive Cancer Network continues to recommend adjuvant chemotherapy or chemotherapy combined with chemoradiation therapy for patients with resected pancreatic cancer. ${ }^{8}$ We designed this study using the National Cancer Database (NCDB) to evaluate treatment trends for patients with resectable pancreatic cancer.

\section{Methods}

The National Cancer Database is a national oncology outcomes database for over 1,500 Commission on Cancer accredited cancer programs. The NCDB is a joint program of the American College of Surgeon's Commission on Cancer and the American Cancer Society. Institutional Review Board approval was received from our institution to access the database for this study; the database was accessed on February 15, 2013.

Patients diagnosed with stage I and II pancreatic adenocarcinoma between 2003 and 2010 were selected from the NCDB Hospital Comparison Benchmark Reports. Data available for earlier years was not included because of a change to the American Joint Committee on Cancer staging system in 2003. Attention was paid to the initial treatment regimen, such as surgery alone, surgery plus chemotherapy, or surgery plus chemoradiation. The NCDB does not identify whether additional therapies were given in the adjuvant or neoadjuvant settings. Surgery plus radiation and chemotherapy is referred to interchangeably as "chemoradiation." We designated "nonsurgical therapy" to include chemotherapy only, chemoradiation only, or no first course treatment. The NCDB categorizes patients as receiving "other specified therapy" when the first course treatment does not fall under any of the abovementioned categories. We included these patients in our demographics and trend analysis, but excluded them from the analysis of predictive factors.

We defined private insurance as including managed care and any private insurance. Patients with government insurance included those with Medicaid, Medicare (with or without 
supplement), Veterans Affairs, Tricare/Military, or Indian/Public Health Service. Patient comorbidities are recorded in the NCDB according to the Charlson Comorbidity Score using the Deyo method of mapping administrative codes. ${ }^{9}$ We defined "non-white" ethnicity to include African-American, Hispanic, Asian/Pacific Islander, Native American, and other or unknown.

Data regarding hospital setting were collected and analyzed. The NCDB defined teaching hospitals as facilities associated with university medical schools or those designated as National Cancer Institute Comprehensive Cancer Care Programs. Teaching hospitals make up $18 \%$ of the reporting hospitals and account for $33 \%$ of cases in the NCDB. The NCDB defines community cancer centers as facilities that diagnose or treat 100-649 cancer cases annually, and comprehensive community cancer centers as facilities that treat 650 or more cancer cases annually. In this study, we considered community and comprehensive community cancer centers together and refer to them generally as "community hospitals." Community hospitals make up $74 \%$ of all reporting hospitals and account for $63 \%$ of cases in the NCDB. Hospitals that do not fulfill these criteria were categorized as "other" and make up the remaining portion of reporting hospitals in the NCDB.

We compared treatment trends over the 2003-2010 period with respect to type of treatment received, stage of pancreatic cancer, and hospital setting. The Cochran-Armitage test for trend was used to assess changes in treatment over time. We also compared demographics between the two hospital settings and assessed univariate factors influencing odds of a patient receiving surgery. Percent change is reported as change relative to 2003 treatment rates. Pearson's chi-squared test was used to compare categorical variables. The level of statistical significance was set to $P<0.05$. All reported $P$ values are two-tailed. Statistical analysis was done using JMP Pro 10.0 (Cary, NC) and GraphPad Prism 6 (La Jolla, CA).

\section{Results \\ Demographics}

A total of 59,094 patients with stage I and II pancreatic adeno-carcinoma were included in the study. Table 1 shows patient demographics at community and teaching hospitals. With few exceptions, comparison between the two hospital settings for each patient demographic yielded a statistically significant difference. More patients in $>80$ age range were treated at community hospitals ( $24 \%$ ) compared to teaching hospitals $(16.2 \%)$; the proportion of patients in each age group was significantly different between hospital settings ( $P<0.05$ for all). Community and teaching hospitals treated nearly equal portions of women (52.0 vs. $50.3 \% ; P<0.0001)$. Stage II disease was more commonly treated at teaching hospitals (76.3 vs. $69.1 \% ; P<10.0001)$. The majority of patients had a Charlson comorbidity score of zero $(68 \%)$. Patients traveling over 50 miles were more likely to receive care at teaching hospitals than those traveling under 50 miles (odds ratio [OR] 3.18, 95\% confidence intervals [CI] 3.042 to $3.313, P<0.0001$ ). 


\section{Use of Surgery for Resectable Pancreatic Cancer}

Since 2003, within each hospital setting, there has been no significant change in the rate at which patients with stage I or II pancreatic cancer receive surgery as a component of therapy. However, a comparison of hospital settings does reveal differences in the use of surgery as a component of therapy. Patients with stage I disease in 2010 received surgery at a rate of $31.8 \%$ at community hospitals and $52.9 \%$ at teaching hospitals $(P<0.0001)$ (Fig.

1a). Patients with stage II disease in 2010 received surgery at a rate of $53.0 \%$ at community hospitals and $60.3 \%$ at teaching hospitals $(P<0.0001)$ (Fig. 1b).

\section{Use of Surgery Alone}

Use of surgery alone for treatment of stage I pancreatic adenocarcinoma did not change significantly at community or teaching hospitals from 2003 to 2010. In 2010, of stage I patients who underwent surgery, 66.4 and $64.6 \%$ received surgery alone at community and teaching hospitals, respectively ( $P$ value not significant) (Fig. 2$)$. Use of surgery alone for stage II disease decreased significantly in both hospital settings over the observed period $(P$ $<0.0001$ for both). Of stage II patients who underwent surgery at community hospitals in 2010, 33.6 \% received surgery alone, representing an $11.0 \%$ decrease from 2003 (Fig. 3a). Similarly, of patients with stage II disease who underwent surgery at teaching hospitals in 2010, $38.7 \%$ received surgery alone, a $20.8 \%$ decrease from 2003 (Fig. 3b). Stage II patients received surgery alone more frequently at teaching hospitals compared to community hospitals $(P=0.0009)$.

\section{Use of Radiation and Chemotherapy in Addition to Surgery}

The use of surgery, radiation, and chemotherapy (SRC) decreased significantly across both stages at community and teaching hospitals $(P<0.0001$ for all). Of patients with stage I disease who underwent surgery at community hospitals in 2010, $19.4 \%$ received SRC, a $42.2 \%$ decrease from 2003 (Fig. 2a). Likewise, of stage I patients at teaching hospitals who underwent surgery in 2010, $19.3 \%$ received SRC, a $36.5 \%$ decrease from 2003 (Fig. 2b). There was no significant difference in the rate of SRC for stage I disease at community hospitals compared to teaching hospitals. Of patients with stage II disease who underwent surgery at community hospitals, $39.3 \%$ received SRC in 2010, a decrease of $25.8 \%$ (Fig. 3a). Of stage II patients who underwent surgery at teaching hospitals, $29.6 \%$ received SRC in 2010, a 29.8\%decrease (Fig. 3b). Stage II patients received SRC more frequently at community hospitals compared to teaching hospitals $(P<0.0001)$.

\section{Use of Chemotherapy in Addition to Surgery}

Treatment with surgery plus chemotherapy increased significantly at both community and teaching hospitals for stage I and II disease $(P<0.0001$ for all). Of stage I patients who underwent surgery in $2010,14.1 \%$ received surgery and chemotherapy at community hospitals, an increase of $165.9 \%$. Likewise, $16.2 \%$ received surgery and chemotherapy at teaching hospitals, an increase of $175.0 \%$ (Fig. 2). There was no significant difference in the use of surgery and chemotherapy for stage I disease at community hospitals compared to teaching hospitals. Of stage II patients who underwent surgery in 2010, $27.1 \%$ received surgery and chemotherapy at community hospitals, an increase of 190.1\% (Fig. 3a). 
Similarly, $31.8 \%$ received surgery and chemotherapy at teaching hospitals, a $250.4 \%$ increase (Fig. 3b). Stage II patients received surgery and chemotherapy more frequently at teaching hospitals compared to community hospitals $(P=0.0014)$.

\section{Use of Nonsurgical Therapy}

Within each hospital setting, the use of nonsurgical therapy for treatment of stage I disease did not change significantly at community or teaching hospitals in the 2003-2010 period (Fig. 4a). However, a comparison of hospital settings does reveal differences in the use of nonsurgical therapy. Compared to $43.5 \%$ at teaching hospitals $(P<0.0001), 63.3 \%$ of patients with stage I disease received nonsurgical therapy in 2010 at community hospitals. On the other hand, the use of nonsurgical therapy increased significantly at both community hospitals $(P=0.0002)$ and teaching hospitals $(P<0.0001)$ for stage II disease (Fig. $4 \mathrm{~b})$. Compared to $35.8 \%$ at teaching hospitals $(P<0.0001), 43.4 \%$ of community hospital patients with stage II disease received nonsurgical therapy in 2010.

\section{Predictors of Surgery}

Patients under 70 years of age were much more likely to receive surgery than those 70 or older, across both stages, and both hospital settings $(P<0.0001$ for all) (Table 2$)$. White patients with stage I disease treated at community hospitals were less likely to receive surgery than non-white patients (OR 0.88), but white patients with stage II disease were more likely to receive surgery (OR 1.2). White patients at teaching hospitals were more likely to receive surgery than non-white patients with stage I disease (OR 1.2) and stage II disease (OR 1.5).

Patients with a Charlson Comorbidity Score of two or higher were less likely to receive surgery than patients with a score of zero or one, across both stages, and at both hospital settings ( $\mathrm{p}<0.05$ for all). Patients with non-governmental insurance were more likely to receive surgery than patients with government insurance for stage I and II disease at both hospital settings $(P<0.0001$ for all). Patients at community hospitals were less likely to receive surgery than patients at teaching hospitals for both stage I and stage II disease $(P<$ 0.0001 for both) (Fig. 4).

\section{Discussion}

The current study aimed to evaluate changes in the approach to treating resectable pancreatic cancer in the USA using a national oncology database. For both stage I and stage II disease, we found a significantly increased use of surgery plus chemotherapy and a concomitant decreased use of surgery plus chemoradiation therapy at both community and teaching hospitals. Furthermore, the rate of nonsurgical therapy remained alarmingly high, ranging from 36 to $63 \%$ depending on hospital setting and disease stage.

Early randomized trials of adjuvant therapy for pancreatic cancer as well as institutional series studied the use of chemo-radiation and found a survival benefit compared to surgery alone. ${ }^{3,10,11}$ Beginning in the early 2000s, randomized trials have studied chemotherapy alone as adjuvant therapy. ${ }^{4,5}$ They too have shown a survival benefit compared to surgery alone. Taken as a whole, the results of all of these trials have clearly demonstrated a benefit 
to adjuvant therapy after the resection of pancreatic cancer. However, there is no consensus as to the optimal type of adjuvant therapy. In the USA, the National Comprehensive Cancer Network recommends either chemotherapy or chemotherapy combined with chemoradiation therapy, ${ }^{8}$ whereas in Europe, the European Society for Medical Oncology recommends adjuvant chemotherapy. ${ }^{12}$ In either case, novel therapies are desperately needed to further improve survival after the resection of pancreatic cancer. ${ }^{13}$

The data in our study reveal a change in the approach to adjuvant therapy for pancreatic cancer in the USA. From 2003 to 2010, the use of chemotherapy alone increased up to 250 $\%$ depending on the disease stage and hospital setting. During the same time, the use of chemoradiation decreased up to $42 \%$ depending on the disease stage and hospital setting. These findings parallel to some degree the time course of publication of the previously referenced clinical trials. That is to say, with the more recent publication of the trials emphasizing chemotherapy alone, the use of chemotherapy alone started to increase. Despite this increase in the use of chemotherapy alone, in 2010, there remained a slightly greater use of chemoradiation as adjuvant therapy for pancreatic cancer.

The current study does reveal some concerning issues regarding the management of resectable pancreatic cancer. Despite all the evidence showing a benefit to the use of adjuvant therapy for pancreatic cancer, our data show that of those patients who underwent resection of pancreatic cancer in 2010, one third to two thirds did not receive adjuvant therapy. This lack of delivery of adjuvant therapy, while concerning, is not too surprising. Single institution studies have shown that as few as 47 to $74 \%$ of patients receive adjuvant therapy after resection of pancreatic cancer. ${ }^{14,15}$ However, one series demonstrated that 91 $\%$ of patients who had a periampullary cancer resected received adjuvant therapy. ${ }^{16}$ There are a number of reasons why the rate of delivery of adjuvant therapy is so low. They include prolonged postoperative recovery, interval discovery of metastatic disease, social circumstances, and patient refusal. ${ }^{17}$

While the suboptimal delivery of adjuvant therapy for pancreatic cancer is a concern, a more pressing issue is the continued national failure to utilize surgery in the management of patients with resectable pancreatic cancer. Using the National Cancer Database, Sener et al. reported that only $22 \%$ of stage I patients and $8 \%$ of stage II patients had their cancer resected between 1985 and $1995 .{ }^{18}$ Using the same database, Bilimoria et al. showed that from 1995 to 2003, $49.7 \%$ of patients with stage I and stage II disease had their pancreatic cancer resected. ${ }^{19}$ Our analysis of the National Cancer Database from 2003 to 2010 showed that only $43.4 \%$ of patients with stage I disease and only $59.7 \%$ of patients with stage II disease had their pancreatic cancer resected. Though there has clearly been an increased utilization of surgery for resectable pancreatic cancer over the last three decades, there remains a significant portion of patients who do not receive the treatment that has the most important impact on the chances for long-term survival and a potential cure.

With regard to patients who did not receive surgery for early stage pancreatic cancer, Bilimoria et al. found that while the rate of pancreatectomy increased and the percentage of patients not receiving treatment decreased between 1995 and 2004, 38.2 \% of patients were not offered surgery and another $13.5 \%$ had no documented reason for not receiving 
surgery. ${ }^{20} \mathrm{We}$ found a surprisingly high rate of nonsurgical therapy being utilized for treatment of resectable pancreatic cancer. Sixty-three percent of patients with stage I disease at community hospitals and $43.5 \%$ at teaching hospitals did not receive surgery in 2010 . These rates did not change significantly from 2003 . Similarly, $43.4 \%$ of patients with stage II disease at community hospitals and $35.8 \%$ at teaching hospitals did not receive any surgery as part of their first course treatment. These rates, however, increased significantly from 2003 .

Bilimoria et al. found that several factors were associated with patients not receiving surgery including older age, black race, lower annual income, less education, and Medicare or Medicaid insurance. ${ }^{20}$ The report also found that patients were less likely to receive surgery at community hospitals. Here, we report parallel findings of factors associated with a decreased likelihood of receiving surgery. Our univariate analysis demonstrated that patients were less likely to undergo surgery if they were 70 years of age or older, of non-white race, had a Charlson Comorbidity Score of 2 or higher, had government insurance, or were treated at community hospitals. These findings from the 2003-2010 period paired with those of Bilimoria et al. from 1995-2004 indicate that little has changed in patient access to pancreatic surgery in the past two decades. While the use of adjuvant treatment improves, limitations remain in the basic ability to provide patients with surgical therapy for resectable pancreatic cancer. Interestingly, recently presented research by Lee et al. showed that race does not impact treatment and survival in an equal access federal health care system. ${ }^{21}$

Several factors may contribute to the substandard delivery of surgical therapy for resectable pancreatic cancer. Elderly patients often chose to forgo invasive surgery. In 2010, 20.1\% (n $=259)$ of patients with stage I disease and $15.5 \%(n=622)$ of patients with stage II disease at teaching hospitals were age 80 or older. Assuming age as the limiting factor for surgery, then this subpopulation accounts for almost half of all patients who did not receive surgery as part of their first course treatment at teaching hospitals in 2010. It is reasonable to discern that the higher nonsurgical treatment rate at community hospitals is due to an older patient population at these facilities. However, this does not explain why the nonsurgical treatment rate at teaching hospitals has increased significantly from 2003 to 2010.Wemight also attribute the lack of surgical treatment for qualified patients to a lack of medical insurance. However, in 2010, only 30 patients $(2.3 \%)$ with stage I disease and 125 patients (3.1\%) with stage II disease at teaching hospitals reported having no insurance. This assumption would only account for a small part of all patients in 2010 that did not receive surgery as part of their treatment.

Riall and Lillemoe noted two additional possibilities for the lack of surgery in qualified patients: (1) lack of referral to a surgeon for evaluation because of nihilistic views regarding pancreatic cancer among primary physicians, gastroenterologists, and oncologists and (2) surgical evaluation by a surgeon who was not experienced in performing pancreatic resection. ${ }^{22}$ Several studies have documented lower rates of morbidity and mortality as well as increased survival when patients undergo pancreatic resection at high-volume centers. ${ }^{23-25}$ The centralization of treatment for patients requiring complex pancreatic surgery will continue to be a major determinant in patient outcomes, and efforts need to be increased in order to meet the standard of care for early stage pancreatic cancer. 
Furthermore, more progress needs to be made in rapid referral of patients with early stage pancreatic cancer to experienced pancreatic surgeons. It is likely that the systems for an efficient referral system are lacking since research has shown that both primary care and specialist physicians are enthusiastic about using electronic referral systems. ${ }^{26,27}$

Our study has several potential limitations. First, the data available in the NCDB were only accessible in aggregate form and not as individual patient information. As a result, we were limited to only univariate analysis of variables. Second, the patient demographics between community hospitals and teaching hospitals were widely different in some categories, including age and distance traveled for care. These demographic variations may underscore the different rates of treatment utilization between community and teaching hospitals. Third, the NCDB does not identify between adjuvant or neoadjuvant chemotherapy and/or radiation that patients receive. As a result, there may be skewing of the treatment trends since this study intends to study the utilization of adjuvant therapies only.

\section{Conclusion}

The treatment of resectable pancreatic cancer is changing in the USA. An increasing proportion of patients are receiving chemotherapy in addition to surgery with a concomitant decline in the utilization of adjuvant chemoradiation therapy. There remains an unacceptably large percentage of patients with resectable pancreatic cancer who do not receive surgery as a component of their therapy.

\section{Acknowledgments}

The author (SR) would like to thank the Case Western Reserve University School of Medicine for providing support with the Dean's Summer Research Award for first-year medical students.

\section{References}

1. Siegel R, Naishadham D, Jemal A. Cancer statistics, 2012. CA Cancer J Clin. 2012; 62:10-29. [PubMed: 22237781]

2. Stocken DD, Büchler MW, Dervenis C, Bassi C, Jeekel H, Klinkenbijl JH, Bakkevold KE, Takada T, Amano H, Neoptolemos JP. Pancreatic Cancer Meta-analysis Group. Meta-analysis of randomised adjuvant therapy trials for pancreatic cancer. Br J Cancer. 2005; 92:1372. [PubMed: 15812554]

3. Kalser MH, Ellenberg SS. Pancreatic cancer. Adjuvant combined radiation and chemotherapy following curative resection. Arch Surg. 1985; 120:899-903. [PubMed: 4015380]

4. Neoptolemos JP, Dunn JA, Stocken DD, Almond J, Link K, Beger H, Bassi C, Falconi M, Pederzoli P, Dervenis C, Fernandez-Cruz L, Lacaine F, Pap A, Spooner D, Kerr DJ, Friess H, Büchler MW. European Study Group for Pancreatic Cancer. Adjuvant chemoradiotherapy and chemotherapy in resectable pancreatic cancer: a randomised controlled trial. Lancet. 2001; 358:1576-1585. [PubMed: 11716884]

5. Oettle H, Post S, Neuhaus P, Gellert K, Langrehr J, Ridwelski K, Schramm H, Fahlke J, Zuelke C, Burkart C, Gutberlet K, Kettner E, Schmalenberg H, Weigang-Koehler K, Bechstein WO, Niedergethmann M, Schmidt-Wolf I, Roll L, Doerken B, Riess H. Adjuvant chemotherapy with gemcitabine vs observation in patients undergoing curative-intent resection of pancreatic cancer: a randomized controlled trial. JAMA. 2007; 297:267-277. [PubMed: 17227978]

6. Regine WF, Winter KA, Abrams RA, Safran H, Hoffman JP, Konski A, Benson AB, Macdonald JS, Kudrimoti MR, Fromm ML, Haddock MG, Schaefer P, Willett CG, Rich TA. Fluorouracil vs gemcitabine chemotherapy before and after fluorouracil-based chemoradiation following resection 
of pancreatic adenocarcinoma: a randomized controlled trial. JAMA. 2008; 299:1019-1026. [PubMed: 18319412]

7. Neoptolemos JP, Stocken DD, Bassi C, Ghaneh P, Cunningham D, Goldstein D, Padbury R, Moore MJ, Gallinger S, Mariette C, Wente MN, Izbicki JR, Friess H, Lerch MM, Dervenis C, Oláh A, Butturini G, Doi R, Lind PA, Smith D, Valle JW, Palmer DH, Buckels JA, Thompson J, McKay CJ, Rawcliffe CL, Büchler MW. European Study Group for Pancreatic Cancer. Adjuvant chemotherapy with fluorouracil plus folinic acid vs gemcitabine following pancreatic cancer resection: a randomized controlled trial. JAMA. 2010; 304:1073-1081. [PubMed: 20823433]

8. National Comprehensive Cancer Network GuidelinesVersion 2.2012 - Pancreatic Adenocarcinoma. 2012 Available at www.ncen.org.

9. Deyo RA, Cherkin DC, Ciol MA. Adapting a clinical comorbidity index for use with ICD-9-CM administrative databases. J Clin Epidemiol. 1992; 45:613-619. [PubMed: 1607900]

10. Klinkenbijl JH, Jeekel J, Sahmoud T, van Pel R, Couvreur ML, Veenhof CH, Arnaud JP, Gonzalez DG, de Wit LT, Hennipman A, Wils J. Adjuvant radiotherapy and 5-fluorouracil after curative resection of cancer of the pancreas and periampullary region: phase III trial of the EORTC gastrointestinal tract cancer cooperative group. Ann Surg. 1999; 230:776-784. [PubMed: 10615932]

11. Yeo CJ, Abrams RA, Grochow LB, Sohn TA, Ord SE, Hruban RH, Zahurak ML, Dooley WC, Coleman J, Sauter PK, Pitt HA, Lillemoe KD, Cameron JL. Pancreaticoduodenectomy for pancreatic adeno-carcinoma: postoperative adjuvant chemoradiation improves survival. A prospective, single-institution experience. Ann Surg. 1997; 225:621-636. [PubMed: 9193189]

12. Seufferlein T, Bachet JB, Van Cutsem E, Rougier P. ESMO Guidelines Working Group. Pancreatic adenocarcinoma: ESMO-ESDO Clinical Practice Guidelines for diagnosis, treatment and follow-up. Ann Oncology. 2012; 23:33-40.

13. Hardacre JM, Mulcahy M, Small W, Talamonti M, Obel J, Krishnamurthi S, Rocha-Lima CS, Safran H, Lenz HJ, Chiorean EG. Addition of algenpantucel-L immunotherapy to standard adjuvant therapy for pancreatic cancer: a phase 2 study. J Gastrointest Surg. 2013; 17:94-101. [PubMed: 23229886]

14. Piperdi M, McDade TP, Shim JK, et al. A neoadjuvant strategy for pancreatic adenocarcinoma increases the likelihood of receiving all components of care: lessons from a single-institution database. Journal of the International Hepato Pancreato Biliary Association. 2010; 12:204-210.

15. Sohn TA, Yeo CJ, Cameron JL, Koniaris L, Kaushal S, Abrams RA, Sauter PK, Coleman J, Hruban RH, Lillemoe KD. Resected adenocarcinoma of the pancreas-616 patients: results, outcomes, and prognostic indicators. J Gastrointest Surg. 2000; 4:567-579. [PubMed: 11307091]

16. Hardacre JM. Is there a learning curve for pancreaticoduodenectomy after fellowship training? HPB Surg. 2010; 2010:230287. [PubMed: 21318116]

17. Aloia TA, Lee JE, Vauthey JN, Abdalla EK, Wolff RA, Varadhachary GR, Abbruzzese JL, Crane CH, Evans DB, Pisters PW. Delayed recovery after pancreaticoduodenectomy: a major factor impairing the delivery of adjuvant therapy? J Am Coll Surg. 2007; 204:347-355. [PubMed: 17324767]

18. Sener SF, Fremgen A, Menck HR,Winchester DP. Pancreatic cancer: a report of treatment and survival trends for 100,313 patients diagnosed from 1985-1995, using the National Cancer Database. J Am Coll Surg. 1999; 189:1-7. [PubMed: 10401733]

19. Bilimoria KY, Bentrem DJ, Ko CY, Tomlinson JS, Stewart AK, Winchester DP, Talamonti MS. Multimodality therapy for pancreatic cancer in the U.S.: utilization, outcomes, and the effect of hospital volume. Cancer. 2007; 110:1227-1234. [PubMed: 17654662]

20. Bilimoria KY, Bentrem DJ, Ko CY, Stewart AK, Winchester DP, Talamonti MS. National failure to operate on early stage pancreatic cancer. Ann Surg. 2007; 246:173-180. [PubMed: 17667493]

21. Lee S, Tzeng CD, Chang GJ, Fleming JB, Lee JE, Katz MH, Jeffrey RL, Hetz SP. Race does not impact pancreatic cancer treatment and survival in an equal access federal health care system. Presented at Society of Surgical Oncology Cancer Symposium. 2013 Mar 6-9.

22. Riall TS, Lillemoe KD. Underutilization of surgical resection in patients with localized pancreatic cancer. Ann Surg. 2007; 246:181-182. [PubMed: 17667494] 
23. Gordon TA, Bowman HM, Tielsch JM, Bass EB, Burleyson GP, Cameron JL. Statewide regionalization of pancreaticoduodenectomy and its effect on in-hospital mortality. Ann Surg. 1998; 228:71-78. [PubMed: 9671069]

24. Birkmeyer JD, Stukel TA, Siewers AE, Goodney PP, Wennberg DE, Lucas FL. Surgeon volume and operative mortality in the United States. N Engl J Med. 2003; 349:2117-2127. [PubMed: 14645640]

25. Fong Y, Gonen N, Rubin D, Radzyner M, Brennan MF. Long-term survival is superior after resection for cancer in high-volume centers. Ann Surg. 2005; 242:540-547. [PubMed: 16192814]

26. Straus SG, Chen AH, Yee H Jr, Kushel MB, Bell DS. Implementation of an electronic referral system for outpatient specialty care. AMIA Annu Symp Proc. 2011; 2011:1337-1346. [PubMed: 22195195]

27. Kim-Hwang JE, Chen AH, Bell DS, Guzman D, Yee HF Jr, Kushel MB. Evaluating electronic referrals for specialty care at a public hospital. J Gen Intern Med. 2010; 25:1123-1128. [PubMed: 20512531]

\section{Appendix}

\section{Discussant}

Dr. John Allendorf (New York, New York): We know that the patients with pancreatic cancer who do the best and live the longest are the ones who undergo surgical resection and we often lament that only $15 \%$ of patients present with resectable disease. But, Dr.

Hardacre and soon to be Dr. Raigani remind us that actually far fewer patients than this actually get to an operating room. Even more startling is the finding that there has been no improvement in the years that have elapsed since Drs. Bilimori and Talamonti brought this to our attention. The authors of this paper should be commended for not letting this issue rest.

I have three questions:

1. Most of the work done on this issue utilizes the national cancer database. Have the authors considered querying other large national databases or large institutional databases to corroborate their findings using similar methods?

2. The overriding bias in this paper, likely held by many of us in the room, is that the reported rate if surgery is unacceptably low. However, the target, acceptable, or appropriate rate of surgical treatment is certainly less than $100 \%$. Could the authors comment on what they think the appropriate target rate for surgical resection ought to be?

3. Many patients who are radiographically stage I or II by initial CT scan will later be found to be stage III or stage IVby additional imaging or at surgical exploration. So, how does and at what point does the patient get assigned to a stage in the database and how might this affect your results?

\section{Closing Discussant}

Mr. Siavash Raigani: Thank you Dr. Allendorf for your comments and questions. We originally set out on this project to assess trends in the adjuvant treatment of pancreatic cancer. We had noticed at our institution that more patients seemed to be getting 
chemotherapy in the adjuvant setting instead of multimodality therapy. We were therefore interested in seeing if this was a more widespread phenomenon. Our data have shown that it is, but they have also shown the persistence of an inability to get patients with resectable pancreatic cancer the therapy that has the greatest impact on outcome.

With regard to your first question, we are not aware of other national databases that would be able to provide the information needed to corroborate or refute our results. Should anyone know of such a database, we would certainly be interested in doing so.

With regard to staging, the NCDB uses a combined AJCC stage group, which includes the pathologic stage group augmented by the clinical stage group where the pathologic stage is not recorded. This combination minimizes the number of cases without an AJCC stage and avoids exclusion of nonsurgical cases from review.

Finally, you asked what we think an appropriate utilization of surgical resection would be. In this study, $\sim 20 \%$ of the patients were age 80 or greater. Of that group, one would think that $50-75 \%$ are not appropriate for pancreatic resection. This brings us to $85-90 \%$ of the entire study population. If we subtracted another $5-10 \%$ for patients not amenable to resection, we enter the $75-85 \%$ range, which we think is a reasonable target for a resection rate. 
a Surgical Resection Rates for Stage I Pancreatic Cancer, 2003-2010

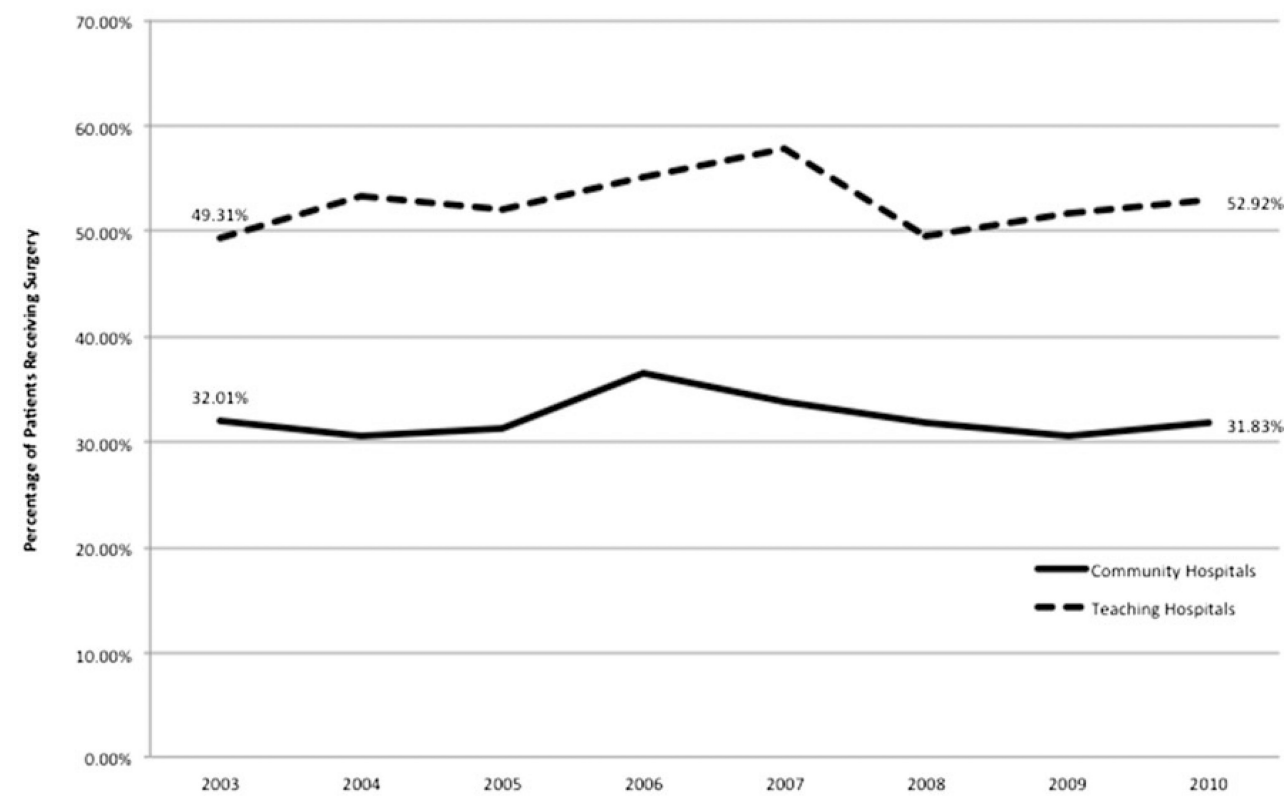

b Surgical Resection Rates for Stage II Pancreatic Cancer, 2003-2010

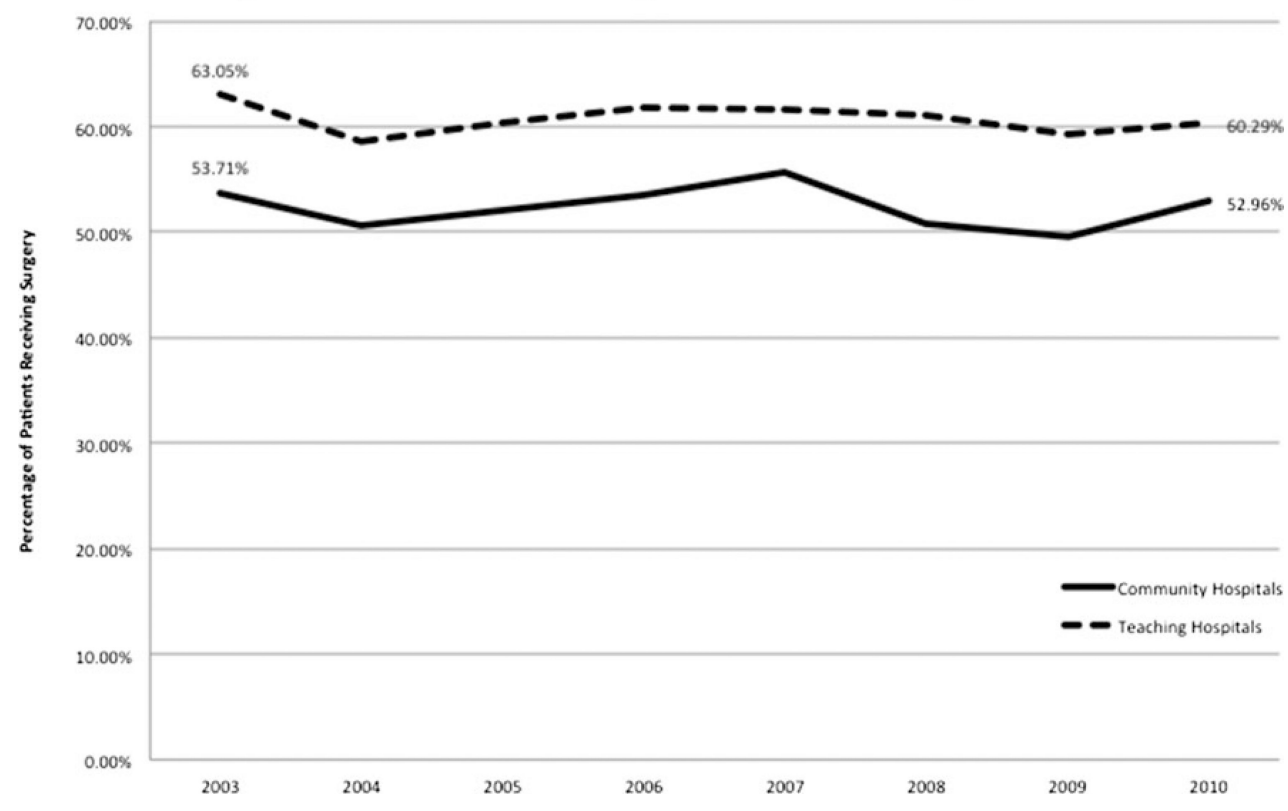

Fig. 1.

a Surgical resection rates for stage I pancreatic cancer, 2003-2010. b Surgical resection rates for stage II pancreatic cancer 2003-2010 
a

Distribution of Adjuvant Therapy for Patients with Stage I Pancreatic Cancer Receiving Surgery at Community Hospitals, 2003-2010

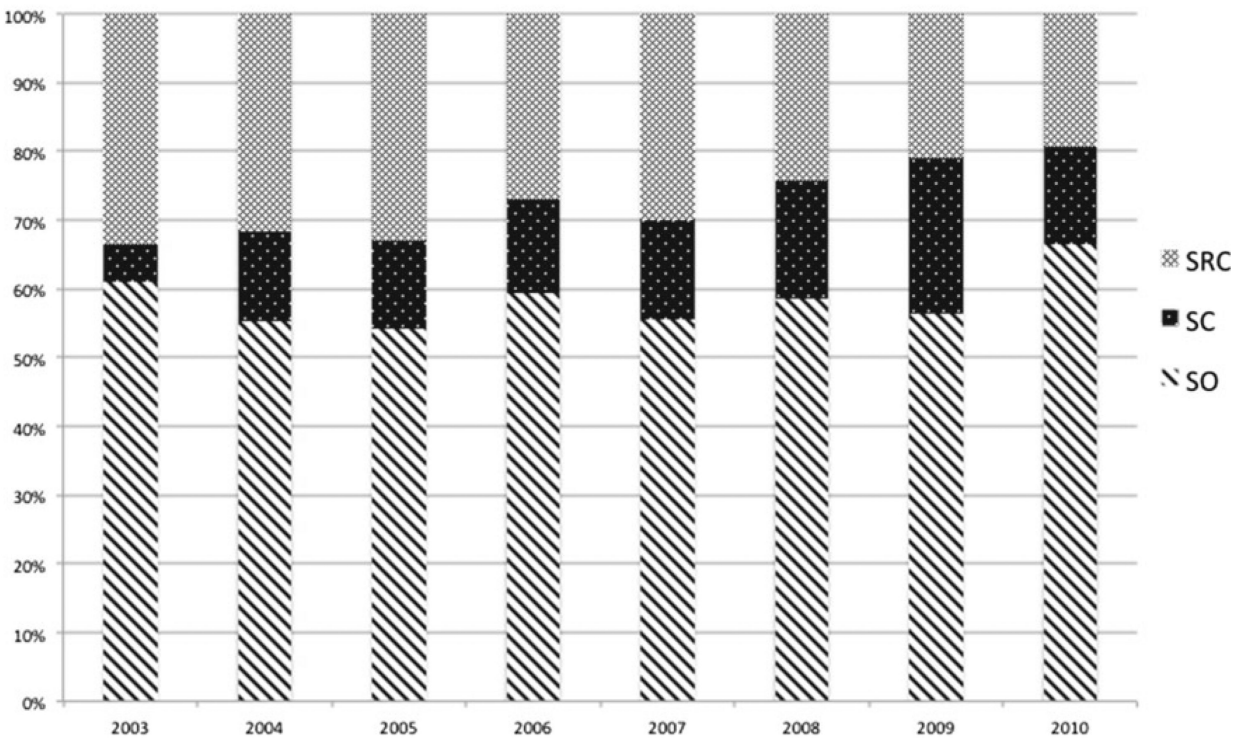

*SO = Surgery only, $\mathrm{SC}=$ Surgery plus chemotherapy, $\mathrm{SRC}=$ Surgery, radiation and chemotherapy

b Distribution of Adjuvant Therapy for Patients with Stage I Pancreatic Cancer Receiving Surgery at Teaching Hospitals, 2003-2010

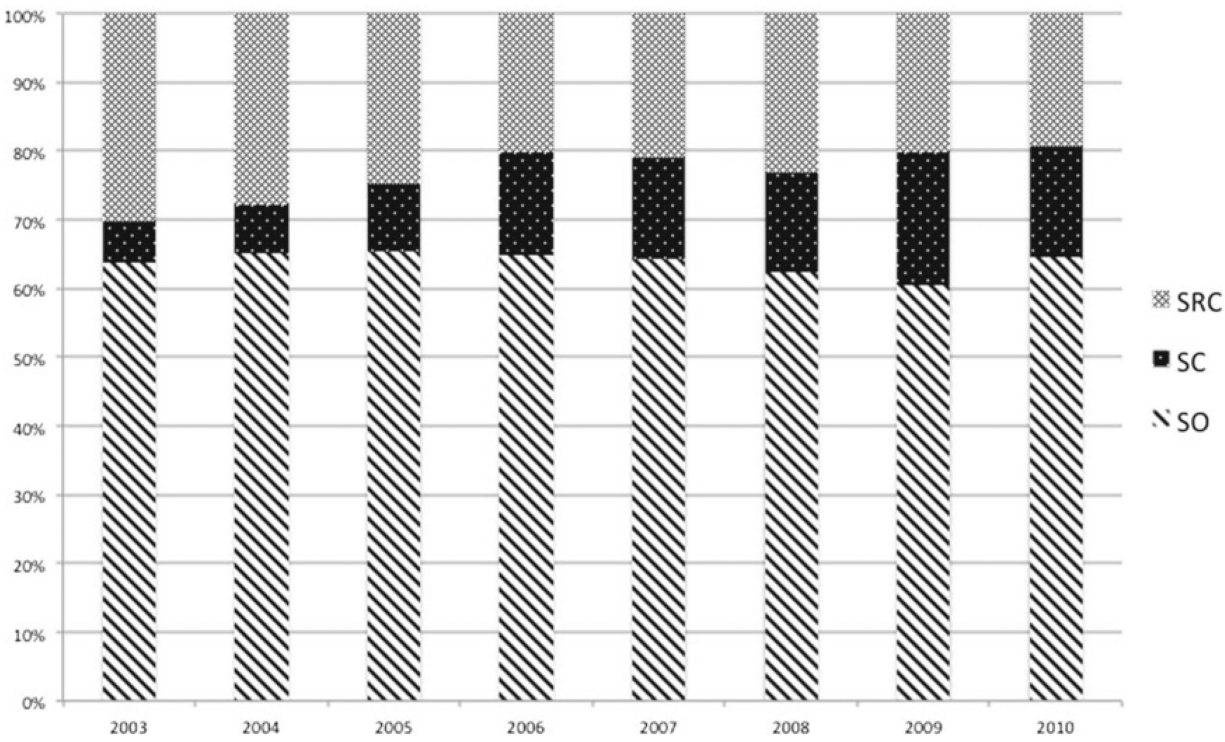

Fig. 2.

a Distribution of adjuvant therapy for patients with stage I pancreatic cancer receiving surgery at community hospitals, 2003-2010. SO surgery only, $S C$ surgery plus chemotherapy, $S R C$ surgery, radiation, and chemotherapy. b Distribution of adjuvant therapy for patients with stage I pancreatic cancer receiving surgery at teaching hospitals, 2003-2010 
a

Distribution of Adjuvant Therapy for Patients with Stage II Pancreatic Cancer Receiving Surgery at Community Hospitals, 2003-2010

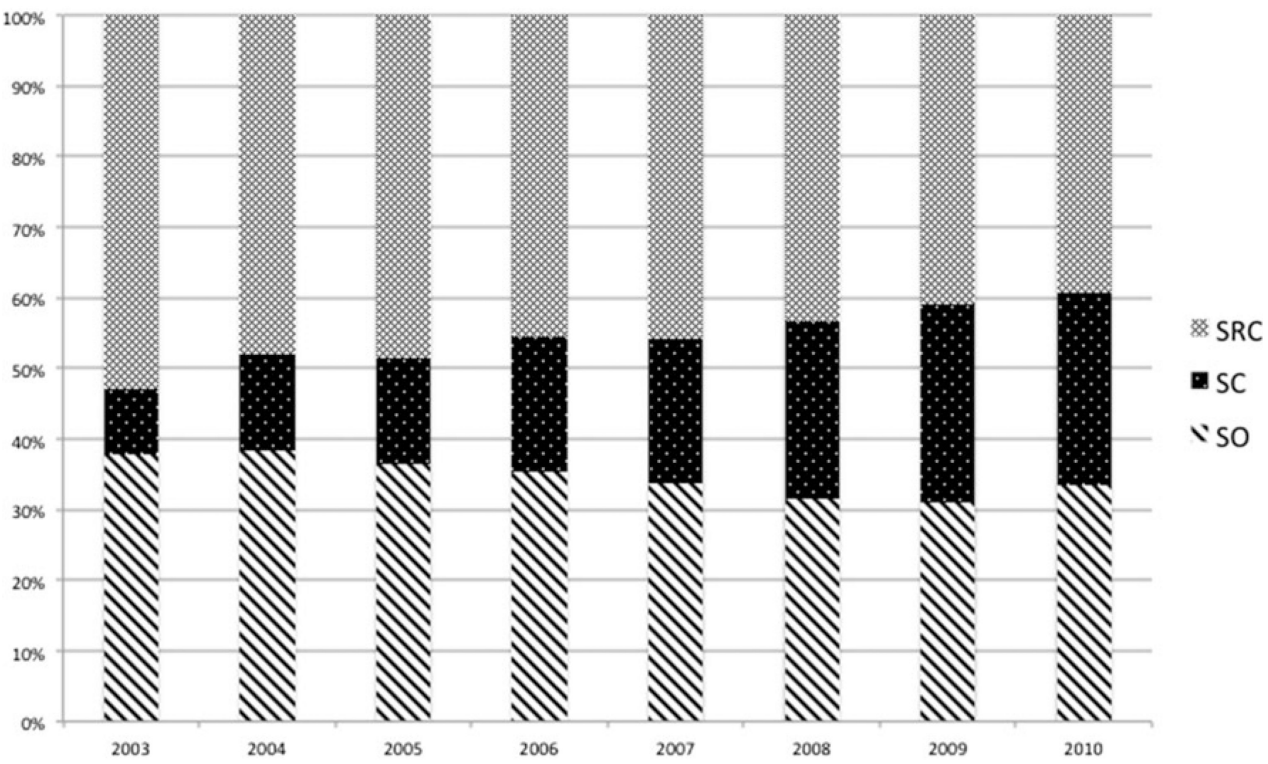

b

Distribution of Adjuvant Therapy for Patients with Stage II Pancreatic Cancer Receiving Surgery at Teaching Hospitals, 2003-2010

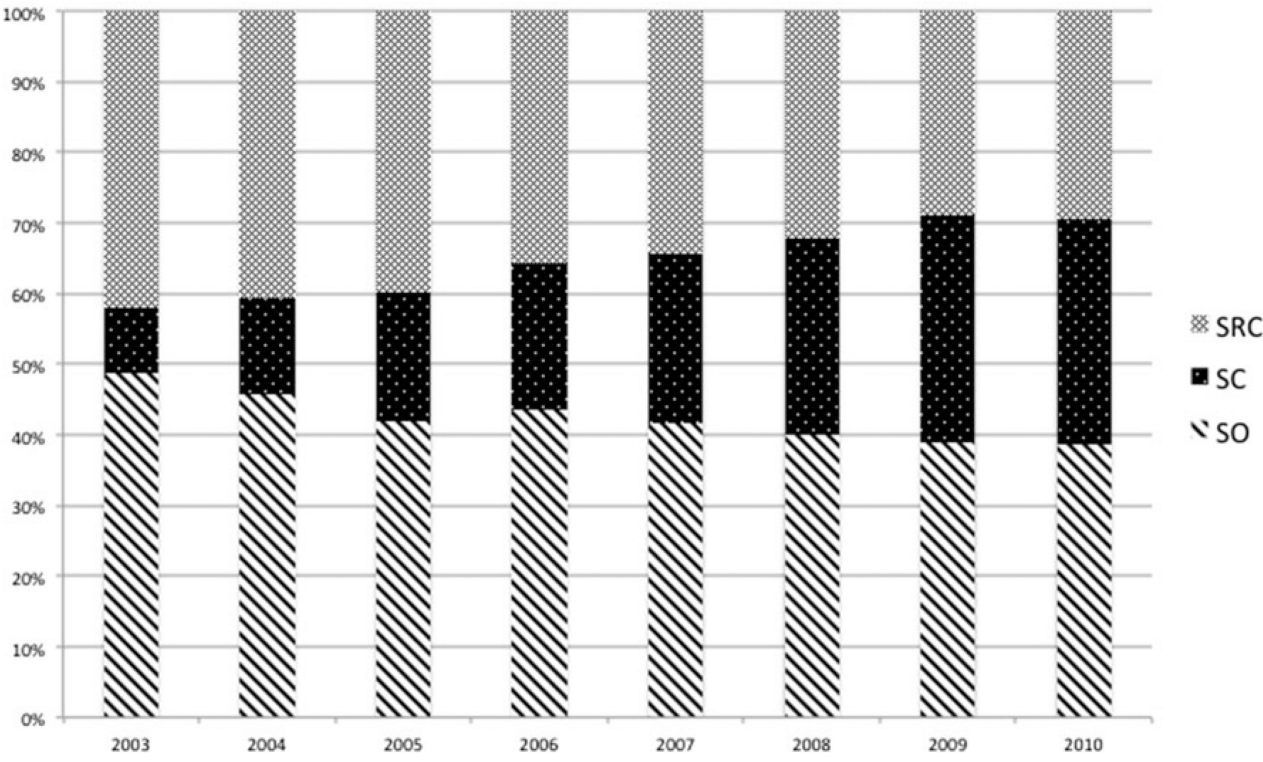

Fig. 3.

a Distribution of adjuvant therapy for patients with stage II pancreatic cancer receiving surgery at community hospitals, 2003-2010. b Distribution of adjuvant therapy for patients with stage II pancreatic cancer receiving surgery at teaching hospitals, 2003-2010 
a Use of Non-Surgical Therapy for Stage I Pancreatic Cancer, 2003-2010

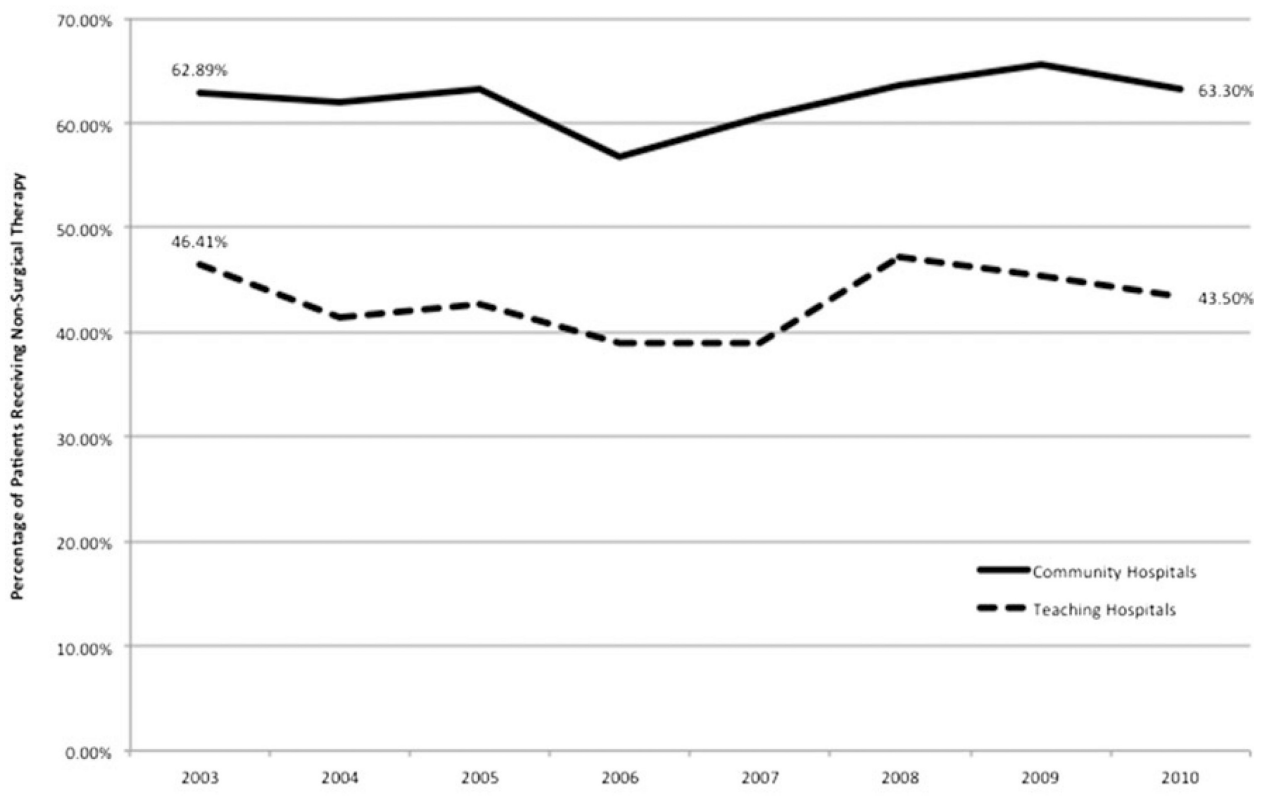

b Use of Non-Surgical Therapy for Stage II Pancreatic Cancer, 2003-2010

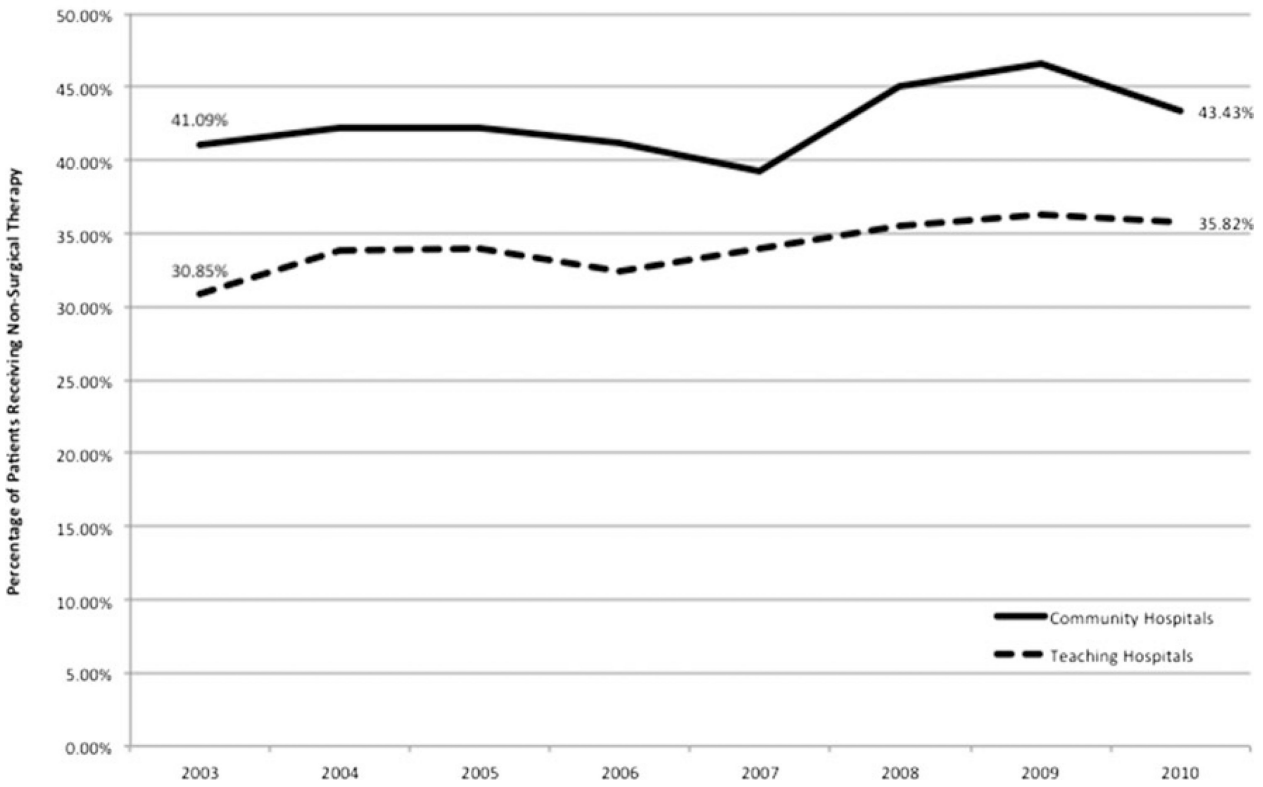

Fig. 4.

a Use of nonsurgical therapy for stage I pancreatic cancer, 2003-2010. b Use of nonsurgical therapy for stage II pancreatic cancer, 2003-2010 


\section{Table 1}

Patient demographics

\begin{tabular}{|c|c|c|c|c|}
\hline \multirow[b]{2}{*}{ Total patients } & \multicolumn{2}{|c|}{ Community Hospitals } & \multicolumn{2}{|c|}{ Teaching Hospitals } \\
\hline & $\begin{array}{l}n \\
28,795\end{array}$ & Percent & $\begin{array}{l}n \\
30,299\end{array}$ & Percent \\
\hline \multicolumn{5}{|l|}{$\operatorname{Age}^{a}$} \\
\hline$<50$ & 1,613 & 5.60 & 2,394 & 7.90 \\
\hline $50-59$ & 4,197 & 14.58 & 5,504 & 18.17 \\
\hline $60-69$ & 7,085 & 24.60 & 8,629 & 28.48 \\
\hline $70-79$ & 8,972 & 31.16 & 8,869 & 29.27 \\
\hline $80-89$ & 6,040 & 20.98 & 4,478 & 14.78 \\
\hline 90 and over & 888 & 3.08 & 425 & 1.40 \\
\hline \multicolumn{5}{|l|}{ Gender $^{a}$} \\
\hline Female & 14,974 & 52.00 & 15,241 & 50.30 \\
\hline \multicolumn{5}{|l|}{ Race/ethnicity ${ }^{a}$} \\
\hline White & 23,853 & 82.84 & 23,788 & 78.51 \\
\hline Non-white & 4,942 & 17.16 & 6,511 & 21.49 \\
\hline \multicolumn{5}{|l|}{ Insurance status $^{a}$} \\
\hline Not insured & 609 & 2.11 & 906 & 2.99 \\
\hline Private insurance & 8,598 & 29.86 & 10,725 & 35.40 \\
\hline Government insurance & 19,192 & 66.65 & 17,570 & 57.99 \\
\hline Insurance status unknown & 396 & 1.38 & 1,098 & 3.62 \\
\hline \multicolumn{5}{|l|}{ Stage $^{a}$} \\
\hline I & 8,900 & 30.91 & 7,175 & 23.68 \\
\hline II & 19,895 & 69.09 & 23,124 & 76.32 \\
\hline \multicolumn{5}{|l|}{ Charlson Comorbidity Score ${ }^{a}$} \\
\hline 0 & 19,095 & 66.31 & 21,099 & 69.64 \\
\hline 1 & 7,313 & 25.40 & 7,186 & 23.72 \\
\hline$\geq 2$ & 2,387 & 8.29 & 2014 & 6.65 \\
\hline \multicolumn{5}{|l|}{ Distance traveled ${ }^{a}$} \\
\hline$<10$ miles & 1,1918 & 41.39 & 6,969 & 23.00 \\
\hline 10-24 miles & 7,799 & 27.08 & 6,667 & 22.00 \\
\hline 25-49 miles & 4,039 & 14.03 & 4,911 & 16.21 \\
\hline 50-99 miles & 2,260 & 7.85 & 4,305 & 14.21 \\
\hline$\geq 100$ miles & 1,300 & 4.51 & 5,067 & 16.72 \\
\hline Unknown & 1,479 & 5.14 & 2,380 & 7.86 \\
\hline
\end{tabular}

${ }^{a}$ Indicates a $P$ value $<0.05$ in this demographic between community and teaching hospitals, as calculated by chi-square test 


\section{Table 2}

Predictors of surgery

\begin{tabular}{|c|c|c|c|}
\hline & Received surgery (\%) & Unadjusted odds ratio (95 \% CI) & $P$ value $*$ \\
\hline \multicolumn{4}{|l|}{ Age $(<70)$} \\
\hline Stage I-CH & 54.51 & 4.16 (3.78 to 4.58$)$ & $<0.0001$ \\
\hline Stage I-TH & 69.59 & $3.42(3.09$ to 3.78$)$ & $<0.0001$ \\
\hline Stage II-CH & 66.19 & $2.48(2.34$ to 2.63$)$ & $<0.0001$ \\
\hline Stage II-TH & 70.43 & $1.92(1.82$ to 2.03$)$ & $<0.0001$ \\
\hline \multicolumn{4}{|l|}{ Race (White) } \\
\hline Stage I-CH & 33.51 & $0.88(0.78$ to 0.99$)$ & 0.0362 \\
\hline Stage I-TH & 55.90 & $1.20(1.07$ to 1.34$)$ & 0.0018 \\
\hline Stage II-CH & 55.67 & $1.20(1.11$ to 1.29$)$ & $<0.0001$ \\
\hline Stage II-TH & 65.61 & $1.45(1.36$ to 1.55$)$ & $<0.0001$ \\
\hline \multicolumn{4}{|c|}{ Charlson Comorbidity Score (2 or more) } \\
\hline Stage I-CH & 22.25 & $0.53(0.44$ to 0.62$)$ & $<0.0001$ \\
\hline Stage I-TH & 49.89 & $0.81(0.67$ to 0.98$)$ & 0.026 \\
\hline Stage II-CH & 49.66 & $0.80(0.72$ to 0.89$)$ & $<0.0001$ \\
\hline Stage II-TH & 59.20 & $0.81(0.73$ to 0.90$)$ & 0.0002 \\
\hline \multicolumn{4}{|c|}{ Insurance (private) } \\
\hline Stage $\mathrm{I}-\mathrm{CH}$ & 53.98 & 3.25 (2.94 to 3.64$)$ & $<0.0001$ \\
\hline Stage I-TH & 70.56 & 2.69 (2.41 to 3.00$)$ & $<0.0001$ \\
\hline Stage II-CH & 66.11 & $2.00(1.88$ to 2.14$)$ & $<0.0001$ \\
\hline Stage II-TH & 71.11 & $1.66(1.56$ to 1.76$)$ & $<0.0001$ \\
\hline \multicolumn{4}{|c|}{ Hospital Setting (Community) } \\
\hline Stage I & 34.00 & $0.42(0.40$ to 0.45$)$ & $<0.0001$ \\
\hline Stage II & 54.91 & 0.69 (0.66 to 0.72$)$ & $<0.0001$ \\
\hline
\end{tabular}

J Gastrointest Surg. Author manuscript; available in PMC 2014 August 18. 